\title{
A Fundamentally Confused Document: Situation Reports and the Work of Producing Humanitarian Information
}

\author{
Megan Finn \\ University of Washington \\ Seattle, USA \\ megfinn@uw.edu
}

\author{
Elisa Oreglia \\ SOAS University of London \\ London, UK \\ eo6@soas.ac.uk
}

\begin{abstract}
Situation reports, or sitreps, are documents commonly used by UN agencies and humanitarian NGOs involved in emergency response to disseminate information to and from relief workers in the field. This paper analyzes the information labor involved in producing sitreps, and how it can be used to understand why these documents are described by insiders as "fundamentally confused." Drawing from document analysis and interviews with over one hundred people involved with sitreps, we examine humanitarian information labor in a decentralized, hierarchical, collaborative, political, and competitive work environment. From an empirical perspective, we contribute to CSCW by adding a case study about the situated practice of making humanitarian information, which includes our work as researcher/consultants in reconstructing the details of information gathering and sharing processes in order to improve them. We consider how the work of producing humanitarian information reproduces problematic humanitarian logics.
\end{abstract}

\section{Author Keywords}

Crisis Informatics; Information Labor; Invisible Work; Humanitarianism.

\section{ACM Classification Keywords}

H.m. Information Systems: Miscellaneous.

\section{INTRODUCTION}

Humanitarian intervention relies on people making decisions about a crisis on the basis of what they learn from actors on the ground, often in faraway places. One of the several inputs in this decision-making process are situation reports, or sitreps, documents commonly used by UN agencies, especially the UN Office for the Coordination of Humanitarian Affairs (OCHA), as well as humanitarian NGOs and other organizations involved in emergency response, to disseminate information to/from relief workers in the field. These documents may contain qualitative and numerical descriptions of the situation, and cover a broad range of topics, including security issues, analyses of the humanitarian situation and political context, reports of damage to the local population and physical infrastructure, program planning and progress information, advocacy and media issues, etc. NGO sitreps are typically confidential documents meant for internal use, but OCHA sitreps are public, circulated as printed documents in the field, via email, and on humanitarian emergency websites such as OCHA-funded ReliefWeb.int. Conditions during humanitarian emergencies typically make data collection very difficult; sitreps are subjected to widely varying and at times contradicting expectations from the various groups of people who read them. Despite these challenges, sitreps are supposed to achieve a great deal for various humanitarian actors: they are supposed to help donors understand how to spend their money, and to inform humanitarian workers at the site of crisis about the work of others. To quote one of our project informants, "The sitreps are a fundamentally confused document.",

This paper is based on a case study of OCHA's production of situation reports to document humanitarian crises in 2008-2009. At that time, OCHA's primary role was to coordinate the multitude of humanitarian response actors, and one of its activities was to create a number of "information products" about disasters, including situation reports. Here, we analyze the "information labor" [20-23] that goes into such documents, which is often overlooked even as the necessity of having high quality information about crises is recognized by all participants as a priority. As we will show, though sitreps are valued documents, the work of making sitreps is not. The (sometimes) ease of the global circulation of humanitarian information obscures how difficult it is to produce, but this "contradiction is just the point" [23]. The information labor analytic is useful for revealing the power relations involved in creating sitreps and demonstrates that they reflect complex and contradictory situations, and fundamentally irreconcilable goals. Although our research was conducted in 2008 and 2009, and both the sitrep document and OCHA have changed since then, our analysis of this near history has theoretical implications that are more enduring: that humanitarian information labor is situated in a particular institutional context where the humanitarian information produced about a crisis cannot be separated from the political-economic relations in which the production took place.

The rest of this paper continues with a brief overview of related work in $\mathrm{CSCW}$. We then give a synopsis of our methods and research limitations. We put forth several ideal-typical scenarios that describe how our study collaborators described the sitrep production process. We discuss six elements of humanitarian information labor and show how it shaped the production of sitrep documents: the 
multiple audiences for the sitrep; the difficulty of making information about a disaster; what people who work on sitreps think about the work; the hierarchical and distributed organization of OCHA; the relations amongst international humanitarian actors collaborating on crisis response and competing for funding; and the logic of humanitarian intervention. We finally discuss in detail the idea of "information labor" and how it shapes sitreps.

\section{RELATED LITERATURE}

We situate our work within the scholarship on the information practices of those involved with humanitarian action. In the CSCW community, researchers have highlighted computer-supported distributed crisis response work by the people affected by a disaster and survivors of war $[35,36,52,53,55]$, digital online volunteers $[15,44,56-$ $58]$, and the use of digital communications in crises by professional responders $[25,50]$. Early CSCW papers about crisis informatics focused on how those affected by a disaster make use of ICTs in innovative ways as they make sense of what has happened [55], and engage in information verification $[35,52]$. Many early studies about the use of social media by those affected by a crisis have been about US disasters such as shootings $[45,46]$.

The focus of this paper is on the collaborative work of humanitarian response professionals to produce humanitarian information in an international context. Although, as we will argue below, the specific institutional context of humanitarian work is crucial for understanding the information produced, our work speaks to some of the themes developed by $\mathrm{CSCW}$ researchers who examine information-related work in complex human-service oriented (mostly non-profit) organizational environments. Much of this work is focused on access to and adoption of particular ICTs [19], rather than the production of information. Still, many projects note the importance of coordination amongst multiple organizations in non-profit settings [69], though importantly these collaborations often take place amongst organizations competing for funding [17]. In addition to a resource-poor work environment, different organizational structures shape intra- and interorganizational information sharing [18]. Stoll et al describe competition and collaboration in an networked multiorganization environment fighting human trafficking [61]. Though inter-organizational coordination was necessary, it was challenging because of the instability of the other organizations involved, adherence to different "collaboration modes" in different organizations, and concerns about perceptions of donors, called "saving face" [61]. Relatedly, recent work about Electronic Medical Records finds that they are inscribed with "institutional logics" and the differing documentary goals of coordination and accountability are impossible [45].

Recent scholarship on international humanitarian action and disaster response has focused on volunteer-driven online efforts [15,56-58]. For example, Starbird and Palen describe the "Humanity Road" project, where a group of volunteers organize online to process digital information about a disaster [58]. Their practice is augmented by a variety of digital tools to sort Tweets and coordinate online volunteer activities. Through transparency and intense reflection on processes, these volunteers attempt to produce trustworthy information to impact action "on the ground." The volunteers even adopted the term "sitrep" to describe one product of their work to legitimize it and make it more visible to the professional humanitarian responders. However, the authors note that it is not clear what impact, if any, that this work has on the world of professional humanitarian emergency response at the site of crisis.

Social media such as Twitter are potentially useful to professional disaster response activity [43], but other forms social media are already influential amongst professional disaster responders. Open Street Map (OSM), annotated by volunteers, is being used by humanitarian workers in the context of relief work [44]. However, these tools are not without complications. Geographers have examined how the work of OSM mapping is biased [60]. OSM tools sometimes capture controversies, but other times do not [44]. The work of the digital volunteers with OSM also points to some of the challenges of virtual disaster response noted by media studies scholar Chouliaraki: the work of faraway volunteers sometimes imposes particular readings of an event that those who live there do not possess $[13,14]$.

While much of the $\mathrm{CSCW}$ literature has focused on the information practices of non-professional international crisis responders, Goggins et al have looked at online information sharing practices inside the "walled garden" [25] of professional disaster response institutional networks of government and NGOs. Like sitreps, these private information sharing platforms represent the views of professional humanitarian actors. Goggins et al [25] highlight the work of the "invisible broker" who "connect two networks of activity within APAN [All-Partners Access Network, the platform being analyzed], but is not identifiable from raw post activity." Similarly, we seek to highlight "invisible" information work involved in making sitreps.

Moving outside of the realm of $\mathrm{CSCW}$ literature, recent work in the realm of international humanitarian emergency response is useful to understanding the collaborative work and expertise involved in sitrep production. The resources dedicated to humanitarian action have recently increased [1], and along with them a critique of humanitarian work, from academics [e.g. 1,2,10,11,27,71], humanitarian practitioners [e. g. 34,66], and the press [e. g. 26,29,47,49]. These critics decry the compromises with corrupt governments in order to access affected populations, ask how much money actually reaches the intended recipients versus the humanitarian organizations, question the long term effects of aid on developing economies, and acknowledge the competition for humanitarian funding. 
Furthermore, humanitarian action is supposed to be "distinct from several other projects," such as economic development and the promotion of democracy because humanitarian emergencies "pose immediate moral demands that override other considerations," though it is in fact often intertwined with a state's international policy, and even an instrument of it [11]. Other critiques of humanitarian activity note that donations for international emergencies are often guided most obviously by the number of people killed, but also by colonial relations, language, proximity to a disaster, and the amount of news coverage, not simply the needs of the affected populations [62].

In this work, we move beyond the general critiques of humanitarian intervention to examine humanitarian information production. Specifically, we examine how the issues identified in the critiques of humanitarian intervention shape information labor. We borrow Greg Downey's term information labor [5,20-23] to refer to the work of OCHA situation report document production. Downey, a geographer and historian, examines the labor of managing, consuming, and producing and reproducing what he calls "internetworks" [20], or infrastructures for circulating information. Downey's analysis highlights "invisible" information labor behind the telegram message delivery [21,59] and closed captioning systems [22]. The concept of information labor seeks to make visible the work that makes possible the circulation of information across vast contexts [23]. Furthermore, a close examination of the contradictions in humanitarian information labor help us understand why the sitrep is a "fundamentally confused" document. Downey argues that focusing on "information labor" means highlighting the political economic context, the social meaning of information labor, and how the global circulation of information shapes work [23]. The work of producing sitreps is not exclusively focused on the process of circulating information, but it is about producing information about complex crises that is legible to the cosmopolitan audience of humanitarian actors. We take information labor to include the work of gathering information to include in a sitrep from other humanitarian actors and distilling it into an "information product" to be circulated outside of OCHA.

We also highlight the obstacles that information finds in circulating, in the tradition of "critical information studies" [68]. In studies of disasters, researchers argue that "information flow is the central nervous system for all disaster relief efforts" [30]. Information is a useful concept precisely because it resembles what Latour calls an "immutable mobile" - an entity that can move from one context to another keeping its original properties. However, we argue that information might not have the mobility it is assumed to have. The immutable mobile "information" retains its meaning regardless of context, a sentiment well captured by the powerful metaphor "information flow" $[12,72]$, whereby information can cross social, political, and physical distances,. The materiality of digital documents that can be easily reproduced and conjured on devices all over the world makes the imagination of flow easier [4,24]. However, "Information doesn't suddenly flow out of the categories and classification it is contained in, nor does it jump from one technological platform to another all by itself" [28]. The assumption that information can flow conceals ideological work. Saxenian [51] and Tekhteyev's [64] work on knowledge circulation describes the work that has to be done to move "information" from one place to another. Changing what people know, however, is not just a matter of information technology, or even "information" as an "immutable mobile." Still, the potential of information flow is enticing, and many projects have tried to build software to improve information flow on the assumption that if bits flow, knowledge also flows. By focusing on information labor, contextualized in relations of production, we show that information does not just easily flow, but is painstakingly produced and processed.

Using the lens of "information labor" and "critical information studies" to examine a case of crisis informatics highlights different aspects of collaborative work. Our work extends existing CSCW crisis informatics literature by showing how the conditions of information production are not only embedded in humanitarian information about humanitarian crisis, but critical for understanding it. The challenges involved in making information about disasters that we identify in this article builds on recent work critical of the new tools, epistemologies and practices involved in using "Big Data" for "digital humanitarianism" [8,9,16,54]. While circulating information about humanitarian crisis can be straightforward, at least for people with working internet connections, we show how the interpretation and management of this information must consider the information labor involved in producing it.

\section{BACKGROUND}

Beginning in the early 2000s, OCHA stepped up its efforts to become an "intellectual leader and knowledge broker among the international humanitarian community" [39-42]. Part of this effort consisted in creating a portfolio of documents that included situation reports. Our engagement with the organization began in 2008, following an information management review that identified sitreps as an opportunity to improve OCHA's management of humanitarian emergencies.

Between 2008 and 2009, a team comprising the authors, Nick Rabinowitz, and John Ward worked with a manager in the OCHA information unit to analyze sitreps and suggest ways to improve both the document and the processes of information gathering and sharing around it. As researchers, we were interested in broad questions about disaster information: how are sitreps created and circulated? As consultants, a normative goal motivated our inquiry: how could we improve the process of information gathering and sharing around sitreps? Our ultimate goal was to build an information system to support data sharing and 
collaboration amongst various humanitarian actors. In retrospect, this seems naïve, but it is important to state our initial assumptions. At the end, the major output of the consultative part of this project was a Word template for sitreps, which was adopted in some emergencies, as well as recommendations on how to differentiate sitreps from other information products, and how to streamline their distribution.

In our role as consultants, the sometimes-used document template we produced was a highly unsatisfying result given what we had set out to do; but our real role was to "structure complex messes" [70]. In this paper, we step back into our researcher roles, and drop the normative goals of "improving sitreps" in order to reflect on the work of making humanitarian information. Nonetheless, our normative goals as consultants shaped the interviews, our analysis, and interactions.

\section{Method}

In the course of the project, we spoke to over one hundred people in one-on-one interviews, group interviews, and roundtables. We conducted individual and group interviews over the phone and in person at OCHA headquarters in New York, Geneva, and to a field office over a year and a half in 2008 and 2009. In this article, interviewees are anonymous and identified with the type of organization they work for: OCHA; UN Agency (e.g. UNHCR, UNICEF, WFP, etc.); NGO; and Donor. All of the interviews had at least one interviewer and one note-taker present, but not all were recorded. After each interview, we did extensive debriefings with team members who weren't present at interviews, and triangulated our notes, especially when we did not use a tape recorder.

In order to better understand the insights that emerged from the interviews, and to see if we could substantiate (or not) some of the practical assertions that came up around sitreps, we analyzed a corpus of 101 documents, representing all the OCHA situation reports sent out by OCHA's website ReliefWeb between March 18 and April 25, 2008. For each document, we recorded the issuing office, the date on the sitrep (which at times was different from the date when the document was issued), the number of days covered, if specified, how the document was named. Two people looked at different dimensions of the documents, and classified them according to their content.

Most, though not all, of our interviews were facilitated by several people in OCHA offices in New York and Geneva who work in information management. The other interviewees were with humanitarian actors in the researchers' professional networks. The choice of interviewees was designed to give us a broad view of sitreps. We talked to those who wrote, read, were expected to read, or contributed to situation reports. Most of the interviewees were introduced to us by OCHA officers, and would not have spoken to us without this introduction. This clearly introduced a selection bias in our sample.
Furthermore, because of our collaboration with information management professionals who worked at OCHA headquarters, many people thought of us as members of OCHA though we did our best to reiterate we were not. While we tried to triangulate what we learned from our interviewees through, for example, the sitrep documents themselves, as well as public reports published by a number of the organizations involved with this study, these limitations need to be acknowledged. One other issue needs to be highlighted: while one of the major drivers of the project to improve sitreps was to see the results of humanitarian aid helping the survivors of crisis, those who were the recipients of humanitarian aid do not have an explicit voice in the sitrep and are also absent here.

In the next section, we briefly outline the process that produced the document as we reconstructed it from our fieldwork.

\section{IDEALIZED SITREP PRODUCTION}

There were a number of different ways that a sitrep might come into existence. In a country with a UN OCHA office in place (typically places with protracted humanitarian emergencies like wars), there were people in the country who wrote sitreps, usually an Information Management Officer (IMO). Sitrep documents were shared by field teams to field offices to country office, and then on to the regional and/or global headquarters. Often, sitreps were "cleared" by the head of country team and possibly by headquarters in Geneva and New York. Clearing a sitrep involved OCHA management reading sitreps for form and quality to ensure it was well-written and conformed to the goals of OCHA to coordinate emergency interventions.

Public sitreps like OCHA's depended heavily on the information that sitrep authors collected from other humanitarian actors in the field, particularly from the large International NGOs and UN Agencies with whom they collaborated. Much of the significant communication in the field was verbal. Within an organization, staff members shared updates about the emergencies in general meetings. Between organizations, staff shared information during OCHA coordination meetings. Humanitarian response workers also all had their own personal networks of collaborators and friends that transcended organizational boundaries.

From our interviews, we reconstructed a few generalized scenarios that illustrate how an Information Officer might make a sitrep. The first is when OCHA has a solid infrastructure in place, typically in countries with complex, long-running emergencies (See figure 1). 
Information Gathering in Countries where OCHA Infrastructure is in Place

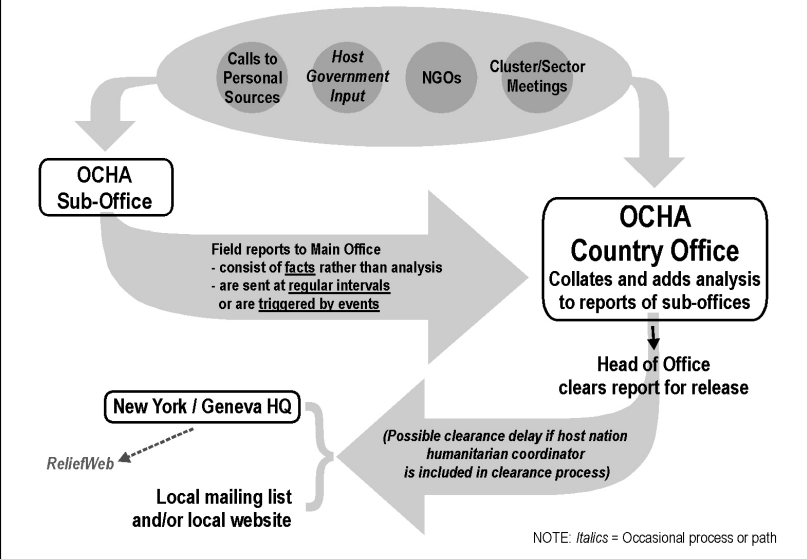

Fig. 1 - Information gathering in countries with an OCHA has a staffed country office in place at the time of an earthquake. A stable network of informants and/or suboffices constantly feeds information to the main country office, which sometimes collects it into databases. The office has sufficient manpower to analyze it, provide cumulative data, and be ready for sudden emergencies.

Given that it is easier to do well in an emergency what is already done well in regular situations, countries with a stable OCHA office were often the best prepared to make sitreps in extraordinary circumstances, because they had the large network of other humanitarian actors necessary to gather content for sitreps already in place.

In the second scenario, OCHA did not already have a country office at the time of a disaster (though often a "Regional" office might have personnel monitoring a given country). OCHA Desk Officers in Geneva or New York might work with groups of people in the region over email to make the sitrep. They would augment reports from their contacts with public documents from other organizations available on ReliefWeb, a public website funded by OCHA which posts humanitarian information from many organizations. They would also use, if available, reports from UNDAC, the United Nation Disaster Assessment and Coordination, a group which is mobilized to disaster-struck countries within a day of the disaster to assess what has happened. This is a description by a Desk Officer at headquarters who had to put together sitreps for a "medium" sized flood in a country with no OCHA presence:

"I created virtual task force with email. Talking with regional office, and Geneva.... I rely on info from the regional office. Do my search on ReliefWeb. Cut and paste from there... When we have an UNDAC team, the meat of the report comes from the UNDAC team." (OCHA)

These are simplified models of two modalities of information gathering, illustrated in Figures 2 and 3:
Information Gathering in Countries Where No OCHA Infrastructure Exists

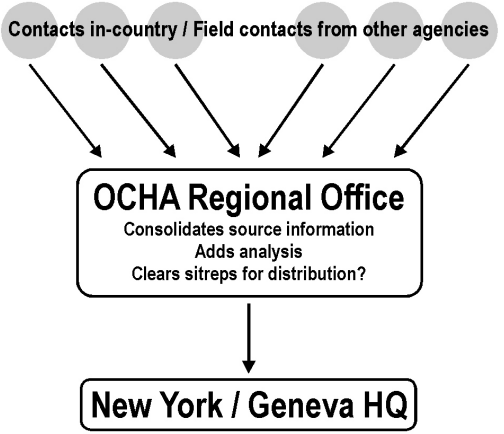

Fig. 2 - Information gathering in countries without an OCHA infrastructure in place

Information Gathering in Emergencies where UNDAC Team is Deployed

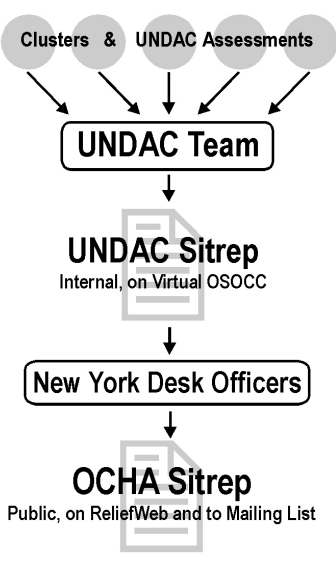

Fig. 3 -Assessment by the UNDAC Team

These models represent how sitrep authors presented their interactions with other organizations within OCHA and the UN in the process of creating a sitrep. The sitrep writers were often confused about how to proceed on "new" crises, especially those who were thrown into the process without a clear idea of the various hierarchies at play. That these models are not always consistent and even confusing is indicative of the complexity of the world in which sitrep authors worked, something we dive into below.

\section{CHALLENGES IN SITREP PRODUCTION}

The idealized version of sitrep production embodies the illusion of information circulating freely, and all actors working towards the same goal of achieving an objective description of the emergency and what is needed to address it. The reality is different: information for sitreps has to come from diverse actors who do not always have an incentive to share it. It has to be put together by people who are trying to serve different and at times incompatible 
audiences. It passes through many different offices, each adding or deleting according to what they believe are the priorities the document should address. It is a public document, rather than an internal one, and thus a document of compromise that embodies the politics of the emergency. Furthermore, gathering information about humanitarian crises is often an impossible task. For example, to categorize and count [37] the number of Internally Displaced People in a massive humanitarian emergency requires a significant effort by highly skilled professionals, and even in the best of cases will result in wide approximations.

Here we present six complications in the process of making sitreps: first, the multiplicity of sitrep audiences; second, the hierarchical and distributed organization of OCHA; third, the status of sitrep work; fourth, the unique humanitarian interventionist logic where "neutrality is the basis for access," (Calhoun 2010: 51); fifth, the challenge of making information about a complicated situation; and sixth, the competition and cooperation amongst humanitarian actors with regards to information sharing.

\section{$1^{\text {st }}$ Challenge: The multiple sitrep audiences}

Sitrep authors thought that the document readers included humanitarian actors "in the field" (at the site of a crisis), the managers of humanitarian organizations in New York and Geneva, members organizations who donated to humanitarian response, the governments at the site of the humanitarian emergency and abroad. Each group thus required different details for sitreps to be useful.

The first audience were humanitarian actors who were working physically close to the crisis. They were assumed to be interested in details that enabled what our informants called "operations" or "coordination" of humanitarian action at the site of the emergency. However, most humanitarian actors working at the site of a crisis did not find sitreps useful for operation or coordination. For these people, the main way to share information were meetings and personal contacts. In the words of an OCHA senior manager, "Program staff in big NGOs sit at the same table and already talk about coordination; by the time an OCHA sitrep is being written, tents are already going somewhere." (OCHA).

Another audience was people in OCHA or the UN at headquarters in New York or Geneva who wanted to learn about long-term trends or compare across emergencies for the purpose of resource allocation. These readers did not find sitreps to be useful for these tasks because they did not always give data that would allow comparison. For example, one sitrep might give the number of people in need of educational resources in a refugee camp, while the other sitrep provided no details.

A third audience that sitrep writers cited were the donors, assumed to be interested in the needs of beneficiaries. Some donors saw sitreps as one useful data point in many, but these donors were often not those with access to large resources. Interviews revealed that donors with large resources at their disposal (USAID, ECHO and DFID) had their own network of people they called upon to get the information they needed. One donor explained,

"We never allocate money on basis of OCHA sitreps; the information must be triangulated. It can point you in the right direction, it's part of the picture" (Donor).

These major donors "in the field" often did not even look at OCHA sitreps, because they could not find many of the details they relied on to make decisions:

"[I] don't use [OCHA sitreps]. Issue of digestibility, issue of quality. I looked at the Country $X$ sitrep, very nicely written, no use for me. Fine-tuned, very bland, for public consumption.... I may read it to know what will be coming at us from the media/press." (Donor)

If each audience for the sitrep was disappointed in the document, this begs the question: what was the sitrep good for? Many donors and NGOs valued the sitrep as an official, publicly citable source, representing what an OCHA interviewee defined the "humanitarian consensus":

"There's usually a consensus on reliable data that emerges in the field. By the time it's in an OCHA sitrep, it shouldn't be new to anyone who's reading it. It's an excellent doc for gathering data from multiple agencies." (Donor).

The sitrep was also seen as critical for the purposes of circulating the shared understanding of humanitarian actors:

"Things go better when there's common information, a common viewpoint, even when it's wrong" (Donor). We found that most recipients saw sitreps as ideally filling the role of a "one-stop shop," "data point" or "overview," but almost never a primary basis for decision-making. "On the basis of the situation reports that we have, we can decide that... at least we need more information" (UN Agency). However, because the sitrep was the consensus of the humanitarian actors, one senior manager at OCHA felt that,

"From a historical perspective, that is something that is important, it's a publication that sets the record, that certain things have been agreed upon. It's a baseline for what was the situation at a certain time" (OCHA).

While the sitrep was "bland" for most humanitarian actors to use for decision-making either in situ or farwaway, it represented the scaffolding on which humanitarian action could take place.

\section{$2^{\text {nd }}$ Challenge: The organization of OCHA}

Humanitarian organizations such as OCHA resemble many other corporate organizations where authority and resources reside at the "top," the headquarters in New York and Geneva, while the knowledge about how to operate resides in the field [63]. We build upon the work of researchers who argue that information management in human-service organizations $[17,18,61,69]$, development-oriented NGOs 
[32], and particularly humanitarian organizations [67] must be understood from a different perspective than that of traditional economic organizations. In the sparse literature focused on the use of information systems within humanitarian organizations, researchers have found that while humanitarian actors are accountable "upward" to donors and "downward" to beneficiaries, information technology-related projects are often focused on "upward accountability" only [65]. Similarly, in our work, the information technology project that we focused on, a new sitrep template, was driven by people in New York and Geneva. The needs of "headquarters" configured the work of the information laborers, at the cost of other parties. Senior officials at OCHA and the UN headquarters had to make difficult decisions about where to focus attention and funding.

Sitrep authors were typically junior staff members, who were in the field when possible. Oftentimes this work would be closely supervised by OCHA country office directors. Generally, more senior information managers, usually located at headquarters, would edit the sitreps later. This "clearance" process embodied a complex negotiation between OCHA headquarters and the field. Although most of the people who worked in headquarters had experience working in the field, there remained a tense relationship between the perspective from the field and that at headquarters. Generally, people working at the site of the emergency thought that the sitrep document needed to meet the needs of that emergency, and since every emergency was different, they were content to issue sitreps when they thought it was appropriate in the format that best described the emergency. Sitrep creators in the field were closest to the emergency and generally understood what was happening, but were not always closest to the corridors of power where people decided whether and how to fund humanitarian disaster response. The people who worked at headquarters were concerned about resource allocation across emergencies and relationships with international humanitarian organizations and donors. Often people who worked at headquarters wanted documents to comply with a specific format, so they were consistent across emergencies. People at headquarters thought that consistency would make the sitrep document easier for readers who had to look at documents about many emergencies, particularly donors and UN officials who needed to decide what to fund. Standardizing the sitreps would also allow OCHA to brand the organization and consistently communicate about disaster response, achieving their mandate.

In our research, the difference between these perspectives was exemplified in debates over the headquarters dictating templates. In our role as project consultants, we were often working with a group at headquarters on developing templates for use globally. While these people were enthusiastic about templates, those in the "field" were not. The template was a locus where the procedures for making sitreps were being fought:
"My experience with OCHA is that if they send you guidelines, then they consider them signed conventions! I'm weary of guidelines and templates, because they're $H Q$ driven, not for us in the field. When we develop them for ourselves, they are different." (OCHA)

OCHA field staff tended to value independence and flexibility instead:

"It's true, we resist standardization, because sometimes it lowers the quality of a good product to suit it to different audiences rather than your specific context" (OCHA).

The standardization of information products walked a fine line between people in the field being able to adapt to a new emergency or innovate on existing information production practices, and the need to serve officials and donors who directed attention, resources and energy. OCHA relied on using different people in different parts of the organization to bring their perspective to the sitrep document. Different people had different understandings of the objectives of the sitrep, which were reflected in the final document. Along with issues of different audiences, and the challenge of making humanitarian information, the low status of information labor, and the hierarchical and distributed structure of OCHA made the document look "confused." The last two challenges of sitrep production further elaborate on the context in which this information labor takes place.

\section{$3^{\text {rd }}$ Challenge: The status of sitrep work}

OCHA was mandated to do "information management" and be a "knowledge broker" in the humanitarian community. Yet, the work of information laborers like sitrep writers, was not well respected within the humanitarian community, even when resources were increasingly dedicated to the task of information management. More experienced officers were typically involved in more hands-on emergency work. Making information products, in contrast, was seen as unattractive work:

"It is just not very sexy.... To be in the hottest emergency and you are not out there doing something in your Land Rover, you are behind your computer or on the phone with people trying to get information or visiting their offices or whatever, it's just not the sexy part of the work." (OCHA).

Though sitreps were valued, the work of writing sitreps was not high status work in the world of humanitarian actors. The combination of sitrep writing as difficult and "not sexy" work is perhaps best captured by a sentence that we heard surprisingly often in the course of our research: sitreps are intended to "feed the beast at headquarters" (OCHA). An NGO interviewee described a sitrep in similar terms:

"It's one of the reasons why sitreps are like, ' $F^{* * *}$, I have to do a sitrep!' Because the amount and the kind of information-it's like a ravenous beast." (NGO). 
During our interviews, we heard several variations on the concept: "We have to be able to feed the beast. We have to give talking points..." (OCHA); sitreps need to "get credible information out and use it for advocacy. They are feeding the internal machine" (OCHA). The idea of a beast fed by sitreps conveys well the feeling expressed by most of our interviewees: sitreps are a burden to put together, write, edit, distribute, and use; they are time-consuming; they are always perceived to be useful to someone else, not to those who produce them; they require a lot of information. It is as if they were humanitarian workers' Sisyphean task, where “...there's an information beast here that needs to be fed all the time-but you can overfeed the beast, and the beast gets tired of it and doesn't want any more." (OCHA). Thus, while on one hand OCHA values information, or at least sees it central to its mission as a "knowledge broker," on the other the people who are supposed to make the sitrep documents were not valued and did not want to do the work. Yet, the outcome of their work, documenting the humanitarian consensus, was of great value to the humanitarian community. The sitrep writers ambivalence towards their work on sitreps might have also reflected their ambivalence towards the logic of humanitarian action more broadly, which is discussed below in more detail.

\section{$4^{\text {th }}$ Challenge: The Logic of Humanitarian Action}

As many researchers have noted, humanitarian action relies on an "emergency imaginary" that "frames these events not as they look to locals, but as they appear to cosmopolitans" [11]. Sitreps are documents written by global humanitarian actors for other cosmopolitans.

Highly debated amongst our interviewees was the question of the limits of what OCHA could include in sitreps, especially now that the internet has made their distribution and archiving much easier and more permanent, and therefore transformed what was originally an internal document into a highly visible one [48]:

"The most difficult job doing the sitrep.... [is] not always putting the truth. You can't say that the local government is not leading the response well, that they are not giving us access. I think that the donors should know. When people call me and ask me then I tell them the situation." (OCHA)

Sitrep creators felt that public sitreps could not report some details of humanitarian emergencies because the politically sensitive nature of these reports would offend another audience: the governments who were allowing humanitarian actors to do their work. Thus, the public nature of sitreps as a defining feature of the document, limited the accuracy of what the sitrep can describe [48]. Backchannels thus were important when it was not safe for humanitarian actors to publicly announce intervention plans. In these cases, sitreps may not represent the private "humanitarian consensus," as described by this OCHA employee:
"The insurgency group is reading the sitreps. Looking at the soft information that we are giving and they put out a press release threatening to blow up food deliveries.... We needed to get them [sitreps] out to the players that we needed to get them out to. There was a swath of information that would get everyone into trouble." (OCHA)

Thus, many OCHA staff felt that the sitrep is an incomplete document, because being involved in humanitarian action meant that often they could not be critical of groups who had the power to stop humanitarian intervention. UN Agencies and NGOs can only operate in emergencies if the country affected grants them permission. External humanitarian intervention is typically welcome only when the host country resources have been overwhelmed. Host countries or groups of people affected by a disaster might want the results of a disaster over-reported so that more aid comes into their country; others might want the results of a crisis under-reported in order to maintain sovereignty or punish the suffering. Sitreps might make it difficult for OCHA to operate in a country, if they anger the host government. But publishing a document that allows the organization to operate often means publishing a watereddown document for public consumption, which might ultimately undermine the authority of OCHA. In some cases, the mere existence of a sitrep is problematic because it indicates the existence of an official emergency. One OCHA employee explained: "The information in the sitrep is not perturbing, the fact that there is a sitrep is the problem" (OCHA). The idea that OCHA did not clearly include information that would anger local authorities feeds into critiques of humanitarian action which argue that humanitarian aid can perpetuate or even worsen humanitarian crises by cooperating with a local government that could be bent on harming an ethnic minority or ignoring the plight of the poor. A UN agency interviewee said:

"You have cases where the government is backing conflict, what do you do? In [a place], I've been negotiating 'droit de passage' [right of passage] with both government and rebels. Sometimes I've even been using the trucks of the army, which is explicitly forbidden.... It's important to reach the beneficiaries." (UN AGENCY)

Interviewees sometimes called the kind of reporting that analyzed the activities of host governments or other groups "political analysis." However, including "political analysis" in sitreps was problematic for their writers. A donor explained:

"To what extent is OCHA mandated political analysis/ protection of civilians? ... It would probably be dangerous for OCHA, but we would like to see them use the humanitarian lens. Recently, for weeks in [place omitted], the sitreps showed the numbers affected as 3000 but we had other figures showing 60000 but OCHA did not have an authorized re-assessment from the host government to correct the number." (Donor). 
Donors with enough resources to get political analyses without OCHA were not interested in seeing OCHA's, as they felt this was beyond its mandate, and not as useful as what they could get from their own sources:

"I don't think that we're looking to OCHA for political analysis - they are the coordinating body for humanitarian effort, so we are looking for what are the conditions, what is the response-not policy or political issues. . That's not what our focus is, that's not OCHA's niche either." (Donor).

Conversely, some OCHA interviewees thought that it was difficult to credibly represent the realities of a crisis without some kind of "political analysis." For sitrep writers, there was a difficult balancing act between practical considerations, institutional roles, and external expectations.

\section{$5^{\text {th }}$ Challenge: The difficulty of producing humanitarian information}

Disasters are dynamic and difficult to materialize into "information products" [39-41]. Describing complex humanitarian situations and the response in a concise way requires time, efforts, and resources to count people and understand their circumstances, and to put that information into an easily digestible form for multiple audiences. Among our interviewees, like in much academic literature, there was often an assumption that "information" simply exists out in the wild, to be plucked up into a sitrep or some other document [38]. In fact, all of the data in a sitrep was a result of laborious and complex work involving many people working for many organizations, reflecting that information as a concept and the artifacts which get called "information" [7] are constructed [6]. Furthermore, the ontological and epistemological process of counting things is not straightforward [37]. The process of making information something that can be fixed in a document and circulated is difficult [31]. The concept of "information" often hid the work that goes into making something like a sitrep.

Furthermore, collecting any data about complex crises was very difficult. For example, OCHA Information Officers had to rely on experts from other NGOs and UN Agencies to get an idea of how many people might be affected by a famine. One of our interviewees, a field officer who worked on issues of security and population displacement, described being in touch on a weekly basis with over 70 NGOs as well as other contacts on the ground in the country with a growing food security problem, and recording the data in a spreadsheet, in order to achieve an estimate of the number of people fleeing the area who were experiencing famine, and crossing international borders as refugees in a different country. As one interviewee put it, "Not everyone can be reduced to a spreadsheet; you need a narrative" (OCHA). On top of the data collected by the UN Agencies and NGOs, OCHA sitrep writers were expected to synthesize the different data points. All the work that this interviewee describes would be conveyed to OCHA in a highly summarized form, and be further summarized into perhaps a bullet point in the final sitrep, hiding all the work, uncertainties, and negotiations behind it. This not only loses all the nuance that is behind a description and that disappears in a number, but also hides the amount of work that takes place to collect even highly unsatisfactory data.

The difficulty of gathering data can be exacerbated by the political motivations of sources. The following quote describes some of the challenges of understanding how many internally displaced people there were as a result of a flood.

"We heard from one ethnic group and they said there was 100,000 displaced. Then the other group said there was nothing and then changed their story. What we saw was a process of inflation about IDPs [internally displaced people]. People in NGOs had sophisticated models of counting IDPS. The government said there was 6,000 [IDPs]. The range was 600,000 to 6,000. We tried to triangulate. We talked to village elders who lied. We wasted a lot of time in terms of resources. We couldn't figure out who the beneficiary population should be." (OCHA)

As this OCHA staff makes clear, even a rough understanding of the size of the population in need is incredibly difficult to know because of the political context of humanitarian crises.

\section{$6^{\text {th }}$ Challenge: Competition and collaboration amongst} humanitarian actors

Traditional research on governance of complex informational environments is problematic when it is applied to humanitarian organizations because there is little recognition that multiple organizations must coordinate [33]. Furthermore, researchers have found that in this multiorganization non-profit context, there is much concern about visibility to funders, and competition for resources $[17,18,61]$.

In the multi-organizational setting where OCHA operates, not only must the producers of sitreps take into account the intricacies of the organization that employs them, but also the fact that, as OCHA, they are not necessarily the organization that responds to disasters. OCHA is coordinating the hundreds of organizations that are involved. In the last decades, there has been a large increase in spending on humanitarian disaster response and a proliferation in organizations and workers involved with humanitarian disasters [3]. Increased financial resources directed towards humanitarian intervention have corresponded to an increase of people and material goods moving to an area with an emergency, as well as an emphasis on coordination, and accountability. Organizations like OCHA are in charge of coordinating all the actors, and have developed with the increases in humanitarian budgets and number of actors. Pre-disaster organization-spanning relationships are key to cross- 
organizational information sharing in disaster response (Kapucu 2006). Thus, producing a sitrep report requires excellent relationships with other humanitarian organizations. Most of the information in OCHA sitreps typically comes from NGOs and UN Agencies that are working directly with people affected by a disaster.

A considerable obstacle to information sharing was that actors in the field were often in competition for funding, publicity, and resources. Collaboration required time, which many NGO staff members did not have, and drained resources needed for actual humanitarian action. It was also often perceived as a burden that would not get reciprocated, as the sitreps did not seem to provide enough new information to NGOs to make worth their time sharing their own data, as this informant explains: "Information should always be both ways, if it's only one-way, I might do it for a while, then I'll stop" (NGO). The sentiment was widespread among NGO informants, although some were more willing to recognize OCHA's value:

"If OCHA can provide good information, we're happy to share our information. It's getting something out of it. In a place like [name omitted] where the government had put in place very confusing regulations on $N G O$ s, going to OCHA forums was really helpful because they would take on some of those issues, and work with the government to provide clearer regulations." (NGO)

The emergency relief environment is highly competitive, as different agencies and NGOs were competing for funding of their projects, and thus for visibility in sitreps. Sitreps are perceived as a vehicle for visibility:

"(We get feedback) mainly from NGOs, because they want our sitreps to reflect their work... All acknowledge that it's useful, but they complain that their work is not reflected on sitreps, and we reply that we're happy to receive on a weekly basis information on what they do, but this never happens, nobody has the time for dedicated Information Officers to sit down and do that every week. Tricky situation, they complain and we tell them give us the information." (OCHA).

Some people who worked for NGOs agreed that visibility in a sitrep was important to them. "I always look for my own stuff, to see if [my agency] is there. If it is, then I look at who else is there; if not, then I call OCHA to complain," (NGO). OCHA staff often highlighted how visibility is an incentive. As one employee said, "it is about being visible. Donors want to see them" (OCHA). But though NGOs and UN Agencies believed that it was important for them to gain visibility through the OCHA sitrep, donors did not agree:

"Does it matter if an NGO is highlighted? Generally no-it means they have funding and can operate. We're really looking at gaps. We might say, oh, this looks great, but we know about NGO reputations based on our own institutional experiences." (Donor).
Our document analysis showed that OCHA sitreps were heavily focused on UN agencies, giving the most visibility to these organizations and their activities. Donors confirmed this:

"OCHA's mandate is to pull it all together, but what we see is in fact a UN sitrep. UN agencies are big players in terms of funding, but even if they are not, OCHA sitreps seem to assume that the UN is the only player in a particular response. So they shortchange their mandate." (Donor)

Moreover, while organizations were sometimes eager to report on their action, they were not eager to talk about where they might be falling short. When asked what they were looking for in OCHA sitreps, our interviewees often answered "context." By this many of the interviewees meant the needs of the local population, the response by local governments and the humanitarian community, and the unmet needs, referred to as the gap. The responseneeds-gap triad was, however, often missing for a variety of reasons, the most frequent being that the sitrep authors did not know what they were. The majority of our interviewees, including OCHA staff, expressed considerable frustration over the difficulty in providing context, as this was seen as the real value added that the organization could provide. As one donor explained,

"What is frustrating is that they [OCHA] don't put things in a context. [Sitreps say] this agency delivered this aid [with] no context. Most useful things-needs out there, this is provided, this is the gap-that's what I feel people wanted to know. Now as a desk officer it's like OK, but this doesn't really say anything about the situation" (Donor).

This was confirmed by our document analysis, which showed that every single sitrep featured details about the response that was being carried out, but rarely matched it to actual, reported gaps. Context also referred to the big picture of the crisis, but it was not straightforward what context OCHA could include, and what content would be read as OCHA overstepping its mandate of "coordination," as we saw above in the $5^{\text {th }}$ challenge. Thus, in an environment of competition for funding and visibility, sitrep authors had the complex role of arbiters of what went into the document that represented the humanitarian consensus on the emergency. A sitrep was often only going to be as good as the relationships that OCHA Information Officers had with UN Agencies, NGOs and other organizations working in the field.

\section{DISCUSSION}

Through our analysis, we highlighted the complexities of sitrep creators' work, which helps explain how a document so vital could also be so "confused."

Downey suggests that there are three analytics for examining information labor that point us towards several conclusions. First, by focusing on information labor, researchers note "how human labor applied to information always takes place in, and depends on, a particular 
spatial/temporal and political-economic context" [23]. In order to write a sitrep, its creators need knowledge about complex organizational structures involved in disaster response, the economic imperatives of humanitarian organizations, interventionist logics, as well as the crisis itself. Notably, the sitreps represent the "humanitarian consensus," as in "the consensus of international humanitarian actors," not the consensus of those affected by a crisis. Thus, the work of sitrep production supports the logic of intervention where well-paid international workers come in to help "victims." Social media holds the promise of broadcasting everyone's voices, but the reality is often that those who are in the most need do not use the platforms, such as Twitter, that many humanitarians, digital and otherwise, listen to. Sitreps, as products of information labor, are inscribed with the political-economic context of humanitarian action. As we described above, their authors must rely on other organizations for details about a crisis. Humanitarian organizations compete with each other for funding, but also must cooperate with each other in responding to a crisis, and providing data for documents like sitreps. This environment incentivizes organizations to produce information that meets their needs either promoting their work or describing a situation so that they can get the resources they seek. Thus sitreps are not merely a document describing a disaster, but a platform for requesting funding. Other humanitarian actors may know how to read between the lines of a sitrep, but the general public may not.

Second, analysts must attend to the social meaning of information labor as enabling and constraining the circulation of information [23]. Sitrep authors did not have high status amongst humanitarian workers, and devalued their own work. This shaped the quality of their work, as assessed by other humanitarian actors, because their status was reflected in their access to other organization and the information that they might be privy to. The status of sitrep work meant that the initial products of sitrep authors were edited before being circulated publicly. Furthermore, the low status of this kind of work makes it easy to underestimate the expertise involved in it. For example, describing the nutritional needs of a population of displaced people requires understanding local food customs, available cooking facilities, energy needs to support meal preparation, existing accessible food supplies, and the number of people to be served. Sitrep authors themselves might not have this expertise, but they often have access to it within their networks. While we are not against the efforts and expertise of "digital humanitarians," and the positive impact this discourse might have on the status of "information labor," attention to the expertise needed in humanitarian information production is also critical.

Third, a focus on how the circulation of information shapes the information labor [23] shows that information laborers were constantly considering the many invited and uninvited audiences for sitrep documents. Sitrep authors hoped that the documents would persuade potential donors to fund humanitarian relief efforts. However, they also had to consider that sitreps might be read by governments or organizations involved in exacerbating the crises. Thus, they had to be sanitized, and facts left out. These incomplete sitreps sometimes compromised the standing of OCHA within the humanitarian community; on the other hand, its ability to deliver aid depended on its presence in, and even cooperation with, unscrupulous state actors. These compromises frustrated sitrep authors and other actors, and further highlight how the production of sitreps is imbued with the logic of humanitarian intervention.

Using Downey's information labor lens to consider humanitarian action, we argue that the environment of humanitarian action is reasserted many times throughout the sitrep creation process, and the lens of "situated information labor" explains why the documents look so "fundamentally confused." These documents reflect a fundamentally confused situation, with contradicting priorities and audiences, and a multitude of constraints. The information laborers embody these contradiction themselves. They do a job that is considered critical in theory, but undervalued and under-resourced in practice, and that is characterized by a series of misaligned incentives. Ultimately, the most significant contribution of our work as consultants has been to make visible the invisible work of sitrep writers, and to highlight how misaligned goals were often visible in the form and content of the document itself. As researchers, we emphasize how all humanitarian information must be read through its context of production (digital volunteers or OCHA employees alike), and that the processes behind it can shed light on the real priorities of the communities involved.

\section{CONCLUSION}

OCHA sitreps never met the expectations of those who made or those who read them-they were too short or too long, provided too little or too much detail, and omitted as much information as they provided. Still, people found them irreplaceable, even as they were expected to perform a variety of often incompatible roles, because they represented the humanitarian consensus on what was publicly citable. By analyzing the complexities of working in a humanitarian setting, we show that the information labor that goes into making sitreps can help us understand why sitreps are "fundamentally confused documents," and why they are faithful representations of the complexity of humanitarian emergencies.

\section{ACKNOWLEDGMENTS}

We thank those who took the time to speak with us in the course of our fieldwork. Nick Rabinowitz was integral to the data collection and analysis presented here. This work was made possible by the support of Robert Glushko and Pamela Samuelson, and funded by Big Ideas @ Berkeley. Megan Finn and Nick Rabinowitz were contract workers with OCHA after the fieldwork reported on above was completed. Airi Lampenen, Janaki Srinivasan, Morgan 
Ames, Daniela Rosner, Jaime Snyder, Lilly Irani, and Mary Gray kindly read drafts of this paper and gave us invaluable feedback.

\section{REFERENCES}

1. Michael N. Barnett. 2011. Empire of Humanity : A History of Humanitarianism. Cornell University Press, Ithaca, NY.

2. Michael N. Barnett and Thomas George Weiss (eds.). 2008. Humanitarianism in Question : Politics, Power, Ethics. Cornell University Press, Ithaca.

3. Michael Barnett and Thomas George Weiss. 2008. Humanitarianism: A Brief History of the Present. In Humanitarianism in Question: Politics, Power, Ethics, Michael Barnett and Thomas George Weiss (eds.). Cornell University Press, Ithaca, NY.

4. Jean-François Blanchette. 2011. A Material History of Bits. Journal of the American Society for Information Science and Technology 62, 6, 1042-1057.

5. Aad Blok and Greg Downey (eds.). 2004. Uncovering Labour Information Revolutions 1750-2000. Cambridge University Press.

6. Geoffrey C Bowker. 1994. Science on the run: information management and industrial geophysics at Schlumberger, 1920-1940. MIT Press, Cambridge, Mass.

7. John Seely. Brown and Paul Duguid. 2000. The social life of information. Harvard Business School Press, Boston.

8. Ryan Burns. 2014. Moments of Closure in the Knowledge Politics of Digital Humanitarianism. Geoforum 53, 51-62.

9. Ryan Burns. 2014. Rethinking Big Data in Digital Humanitarianism: Practices, Epistemologies, and Social Relations. GeoJournal.

10. Craig Calhoun. 2004. A World of Emergencies: Fear, Intervention, and the Limits of Cosmopolitan Order*. Canadian Review of Sociology, April.

11. Craig Calhoun. 2010. The Idea of Emergency: Humanitarian Action and Global (Dis)Order. In Contemporary States of Emergency: The Politics of Miliary and Humanitarian Interventions, Didier Fassin and Mariella Pandolfi (eds.). Zone Books ; Distributed by the MIT Press, Cambridge, MA, 29-58.

12. Manuel Castells. 1996. The Rise of the Network Society. Blackwell, Maiden, MA.

13. Lilie Chouliaraki. 2011. "Improper distance": Towards a critical account of solidarity as irony. International Journal of Cultural Studies 14, 4, 363-381.

14. Lilie Chouliaraki. 2013. Re-Mediation, InterMediation, Trans-Mediation: The cosmopolitan trajectories of convergent journalism. Journalism Studies 14, 2, 267-283.

15. Camille Cobb, Ted McCarthy, Annuska Perkins, et al. 2014. Designing for the deluge: understanding \& supporting the distributed, collaborative work of crisis volunteers. ACM Press, 888-899.

16. Kate Crawford and Megan Finn. 2014. The limits of crisis data: analytical and ethical challenges of using social and mobile data to understand disasters. GeoJournal (November 2014), 1-12.

17. Christopher A. Le Dantec and W. Keith Edwards. 2008. The View from the Trenches: Organization, Power, and Technology at Two Nonprofit Homeless Outreach Centers. Proceedings of the 2008 ACM Conference on Computer Supported Cooperative Work, ACM, 589-598.

18. Christopher A. Le Dantec and W. Keith Edwards. 2010. Across Boundaries of Influence and Accountability: The Multiple Scales of Public Sector Information Systems. Proceedings of the SIGCHI Conference on Human Factors in Computing Systems, ACM, 113-122.

19. Lynn Dombrowski, Amy Voida, Gillian R. Hayes, and Melissa Mazmanian. 2012. The Labor Practices of Service Mediation: A Study of the Work Practices of Food Assistance Outreach. Proceedings of the SIGCHI Conference on Human Factors in Computing Systems, ACM, 1977-1986.

20. Greg Downey. 2001. Virtual webs, physical technologies, and hidden workers: The spaces of labor in information internetworks. Technology and Culture 42, 2, 209-235.

21. Gregory J. Downey. 2002. Telegraph Messenger Boys: Labor, Technology, and Geography, 1850-1950. Routledge, New York.

22. Gregory J. Downey. 2008. Closed Captioning: Subtitling, Stenography, and the Digital Convergence of Text with Television. Johns Hopkins University Press, Baltimore.

23. Gregory J. Downey. 2014. Making Media Work: Time, Space, Identity, and Labor in the Analysis of Information and Communication Infrastructures. In Media Technologies: Essays on Communication, Materiality, and Societ, Tarleton Gillespie, Pablo J. Boczkowski and Kirsten A. Foot (eds.). MIT Press, Cambridge, MA, 141-165.

24. Paul Duguid. 1996. Material Matters: The Past and Futurology of the Book. In The Future of the Book, Geoffrey Nunberg (ed.). University of California Press, Berkeley and Los Angeles, California, 63-102.

25. Sean Goggins, Christopher Mascaro, and Stephanie Mascaro. 2012. Relief work after the 2010 Haiti earthquake: leadership in an online resource 
coordination network. Proceedings of the ACM 2012 conference on Computer Supported Cooperative Work, ACM, 57-66.

26. Peter Gourevitch. 2010. Alms Dealers. The New Yorker. (October 11, 2010) Retrieved May 21, 2015 from http://www.newyorker.com/magazine/2010/10/11/alms -dealers

27. Jennifer Hyndman. 2000. Managing Displacement: Refugees andthe Polics of Humanitarianism. University of Minnesota Press, Minneapolis, MN.

28. Casper Bruun Jensen and Brit Ross Winthereik. 2013. Monitoring Movements in Development Aid: Recursive Partnerships and Infrastructures. MIT Press, Cambridge, MA.

29. Jonathan M. Katz. 2014. The Big Truck That Went By: How the World Came to Save Haiti and Left Behind a Disaster. Palgrave Macmillan Trade.

30. Rebecca Knuth. 1999. Sovereignty, Globalism, and Information Flow in Complex Emergencies. The Information Society, October 2011, 37-41.

31. David M. Levy. 1994. Fixed or fluid?: document stability and new media. Proceedings of the 1994 ACM European Conference on Hypermedia Technology, ACM, 24-31.

32. David Lewis and Shirin Madon. 2004. Information Systems and Nongovernmental Development Organizations: Advocacy, Organizational Learning, and Accountability. The Information Society 20, 2, 117-126.

33. Edgar A. Maldonado, Carleen F. Maitland, and Andrea H. Tapia. 2010. Collaborative systems development in disaster relief: The impact of multi-level governance. Information Systems Frontiers 12, 1, 9-27.

34. Michael Maren. 1997. The Road to Hell: The Ravaging Effects of Foreign Aid and International Charity. Free Press, New York.

35. Gloria J. Mark, Ban Al-Ani, and Bryan Semaan. 2009. Resilience Through Technology Adoption: Merging the Old and the New in Iraq. Proceedings of the SIGCHI Conference on Human Factors in Computing Systems, ACM, 689-698.

36. Gloria Mark and Bryan Semaan. 2008. Resilience in Collaboration: Technology As a Resource for New Patterns of Action. Proceedings of the 2008 ACM Conference on Computer Supported Cooperative Work, ACM, 137-146.

37. Aryn Martin and Michael Lynch. 2009. Counting Things and People: The Practices and Politics of Counting. Social Problems 56, 2, 243-266.

38. Geoffrey Nunberg. 1996. Farewell to the information age. In The Future of the Book, Geoffrey Nunberg (ed.). University of California Press, Berkeley and Los Angeles, California.

39. Office for the Coordination of Humanitarian Affairs. 2007. OCHA Annual Report 2007.

40. Office for the Coordination of Humanitarian Affairs. 2008. OCHA Annual Report 2008.

41. Office for the Coordination of Humanitarian Affairs. 2009. OCHA Annual Report 2009.

42. Office for the Coordination of Humanitarian Affairs. 2010. OCHA Annual Report 2010.

43. Alexandra Olteanu, Sarah Vieweg, and Carlos Castillo. 2015. What to Expect When the Unexpected Happens: Social Media Communications Across Crises. ACM Press, 994-1009.

44. Leysia Palen, Robert Soden, T. Jennings Anderson, and Mario Barrenechea. 2015. Scale in a DataProducing Organization: The Socio-Technical Evolution of OpenStreetMap in Response to Humanitarian Events. Proceedings of the 33rd Annual ACM Conference on Human Factors in Computing Systems, ACM, 4113-4122.

45. Leysia Palen and Sarah Vieweg. 2008. The emergence of online widescale interaction in unexpected events: assistance, alliance \& retreat. Proceedings of the 2008 ACM conference on Computer supported cooperative work, ACM, 117-126.

46. Leysia Palen, Sarah Vieweg, Sophia B. Liu, and Amanda L. Hughes. 2009. Crisis in a Networked World: Features of Computer-Mediated Communication in the April 16, 2007, Virginia Tech Event. Social Science Computer Review 27, 4, 467480.

47. Linda Polman. 2011. The Crisis Caravan: What's Wrong with Humanitarian Aid? Picador, New York.

48. Nicholas Rabinowitz. 2009. The OCHA Sitrep: Open Access and Political Pressure in Humanitarian Information. Masters Thesis. University of California, Berkeley.

49. David Rieff. 2003. A Bed for the Night: Humanitarianism in Crisis. Simon \& Schuster, New York.

50. A. Sarcevic, L. Palen, J. White, K. Starbird, M. Bagdouri, and K. Anderson. 2012. "Beacons of hope" in decentralized coordination: Learning from on-theground medical twitterers during the 2010 Haiti earthquake. Proceedings of the ACM Conference on Computer Supported Cooperative Work, CSCW, 4756.

51. AnnaLee Saxenian. 2006. The New Argonauts: Regional Advantage in a Global Economy. Harvard University Press, Cambridge, Mass. 
52. Bryan Semaan and Gloria Mark. 2011. Technologymediated Social Arrangements to Resolve Breakdowns in Infrastructure During Ongoing Disruption. $A C M$ Trans. Comput.-Hum. Interact. 18, 4, 21:1-21:21.

53. Bryan Semaan and Gloria Mark. 2012. "Facebooking" Towards Crisis Recovery and Beyond: Disruption As an Opportunity. Proceedings of the ACM 2012 Conference on Computer Supported Cooperative Work, ACM, 27-36.

54. Lea Shanley, Ryan Burns, Zachary Bastian, and Edward Robson. 2013. Tweeting up a storm: the promise and perils of crisis mapping. Available at SSRN 2464599. Retrieved May 21, 2015 from http://papers.ssrn.com/sol3/papers.cfm?abstract_id=24 64599

55. Irina Shklovski, Leysia Palen, and Jeannette Sutton. 2008. Finding community through information and communication technology in disaster response. Proceedings of the 2008 ACM Conference on Computer Supported Cooperative Work, ACM, 127136.

56. Kate Starbird. 2013. Delivering patients to sacré coeur: collective intelligence in digital volunteer communities. Proceedings of the SIGCHI Conference on Human Factors in Computing Systems, ACM, 801810.

57. Kate Starbird and Leysia Palen. 2011. Voluntweeters: Self-organizing by Digital Volunteers in Times of Crisis. Proceedings of the SIGCHI Conference on Human Factors in Computing Systems, ACM, 10711080 .

58. Kate Starbird and Leysia Palen. 2013. Working and Sustaining the Virtual Disaster Desk. Proceedings of the 2013 conference on Computer Supported Cooperative Work, ACM, 491-502.

59. Susan Leigh Star and Anselm Strauss. 1999. Layers of Silence, Arenas of Voice: The Ecology of Visible and Invisible Work. Computer Supported Cooperative Work (CSCW) 8, 1-2, 9-30.

60. Monica Stephens. 2013. Gender and the GeoWeb: divisions in the production of user-generated cartographic information. GeoJournal 78, 6, 981-996.

61. Jennifer Stoll, W. Keith Edwards, and Elizabeth D. Mynatt. 2010. Interorganizational Coordination and Awareness in a Nonprofit Ecosystem. Proceedings of the 2010 ACM Conference on Computer Supported Cooperative Work, ACM, 51-60.

62. D Stromberg. 2007. Natural disasters, economic development, and humanitarian aid. The Journal of Economic Perspectives 21, 3, 199-222.

63. Nalini Suparamaniam and Sidney Dekker. 2003. Paradoxes of power: the separation of knowledge and authority in international disaster relief work. Disaster Prevention and Management 12, 4, 312-318.

64. Yuri Takhteyev. 2012. Coding places: software practice in a South American city. MIT Press, Cambridge, Mass.

65. Andrea Tapia and Carleen Maitland. 2009. Wireless Devices for Humanitarian Data Collection: The sociotechnical implications for multi-level organizational change. Information, Communication \& Society 12, 4, 584-604.

66. Fiona Terry. 2002. Condemned to Repeat?: The Paradox of Humanitarian Action. Cornell University Press, Ithaca ; London.

67. Emmanuel Tusiime and Elaine Byrne. 2011. Information Systems Innovation in the Humanitarian Sector. Information Technologies \& International Development 7, 4.

68. Siva Vaidhyanathan. 2006. Afterword: Critical Information Studies. Cultural Studies 20, 2-3, 292315.

69. Amy Voida. 2011. Shapeshifters in the Voluntary Sector: Exploring the Human-centered-computing Challenges of Nonprofit Organizations. interactions $18,6,27-31$.

70. L N Van Wassenhove. 2005. Humanitarian aid logistics: supply chain management in high gear $\dagger$. Journal of the Operational Research Society 57, 5, 475-489.

71. Michael Watts. 1983. On the Poverty of Theory: Natural Hazards Research in Context. In Interpretations of Calamity From the Viewpoint of Human Ecology, Kenneth Hewitt (ed.). Allen \& Unwin Inc., Boston.

72. Frank Webster. 2006. Theories of the Information Society. Routledge, London; New York. 